\title{
The Mixing Speed Effect and Mass of Adsorbent On Copper (Cu) Removal from Wastewater by Water Hyacinth Leaves
}

\author{
Mala Oktaviyana Lussa, Asih Wijayanti, Riana Ayu Kusumadewi*, Rositayanti Hadisoebroto \\ Department of Environmental Engineering, Faculty of Landscape Architecture and Environmental Technology, Universitas Trisakti, \\ Jakarta, Indonesia
}

\begin{abstract}
This study aims to determine the role of water hyacinth leaves powder on wastewater adsorbed from $\mathrm{Cu}$ ion, which is one of the metals responsible for environmental pollution and analyzed using AAS. $\mathrm{Cu}$-wastewater was conducted in bathes and used to optimized the sorption at $250 \mathrm{ml}$, with 10 grams of water hyacinth leaves adsorbents added at speeds of 100, 150, $200 \mathrm{rpm}$, with contact times arrangement of $30,60,90$ minutes. A maximum adsorption rate of 10 grams at a maximum speed of $100 \mathrm{rpm}$, led to a removal efficiency of $98.19 \%$ and 60 minutes contact time. The equilibrium data utilized was properly represented in the Freundlich adsorption isotherm model to analyze the mechanism using $\mathrm{R}^{2} \approx 1$. In addition, $\mathrm{Cu}$ adsorption kinetic models were analyzed using the pseudo-second-order model at an adsorption rate of $\mathrm{R}^{2} \approx 1$. The result showed that the $\mathrm{Cu}$-wastewater used to activate the water hyacinth leaves powder was highly effective for the treatment.
\end{abstract}

\section{Introduction}

The harmful pollution suffered by the environment is due to the continuous growth in industrialization. The contamination in the aquatic environment are harmful to human health, therefore, various efforts have been utilized to purify water through the removal of metals. Activated carbon was used for the removal of metal ions, thereore, it has the potential to be applied as a wastewater treatment [1]. Copper is considered toxic to plants when the concentration is higher than $0.1 \mathrm{ppm}$, however, its water content does not exceed $1 \mathrm{ppm}$, while its concentration toxicity in sheep is above $20 \mathrm{ppm}$. Furthermore, its presence in wastewater appears as a bivalent ion of $\mathrm{Cu}$ (II) or a hydrolytic product. Paint, paper, petroleum and coating industries contain $\mathrm{Cu}$ in there wastewater [2], [3].

There various limitations associated with the use of conventional techniques, in the removal of $\mathrm{Cu}$ through precipitation, electrochemistry, ion exchange and membrane filtration. These limitations include high installation costs, secondary contamination because the use of chemicals and the production of toxic sludge [2], [3]. Furthermore, the use of these techniques does not possess the capability to meet the existing quality standards [4], [5]. Adsorption is defined as a conventional and efficient technology used to remove the toxic pollutants from wastewater. Therefore, it is essential to produce cheap, and available, active carbon adsorbents for removing heavy metal ions from the aqueous environment. Its benefit include reusability, low operating costs, improved selectivity, ability to remove heavy metals from the effluent regardless of its toxicity and short operating time [6].

The adsorption process is preferred than other because the silt-free action and the complete removal of dyes, including diluted solutions. The industrial process widely used carbons because of its ability to adsorb organic compounds. However, there are many disadvantages associated for bleachings, such as higher operational costs and losses, which leads to temperature combustion, pore blocking and hygroscopicity. Studies have recently been conducted to determine cheaper substitutes for activated carbon. These new strategies tend to use cheap and easily available biological and agricultural waste when replacing activated carbon. However, one of the inexpensive adsorbents tested for the dye sorption process is water hyacinth leaves [17].

To determine its practical applicability, a deep investigation was conducted on the removal of $\mathrm{Cu}$ ions by activated carbon from the water hyacinth leaving the biomass in a discontinuous method. Water hyacinth leaf adsorbents were characterized by AAS to determine the adsorption of $\mathrm{Cu}$. The optimum adsorption conditions were analyzed as a function of the mixing speed in agreement with the contact time, and mass adsorbent. Evaluation of mechanisms of $\mathrm{Cu}$ adsorption on water hyacinth leaf adsorbents were conducted in terms of removal efficiency, equilibrium isotherm and kinetic constants.

\footnotetext{
*Corresponding author: rianaayu.kusumadewi @trisakti.ac.id
} 


\section{Materials and methods}

\subsection{Location and Time of Study}

Screen printing wastewater samples were obtained from home industries in Krendang village, Tambora Subdistrict, West Jakarta. This research was conducted in Environmental Engineering Laboratory, Trisakti University, from February to July 2019.

\subsection{Determination of Cu Initial Concentration}

Prior to this research, the heavy metals contained in screen printing wastewater were analyzed on several colors namely, black, white, red, yellow and blue. These metals include copper $(\mathrm{Cu})$, zinc $(\mathrm{Zn})$, titanium $(\mathrm{Ti})$, total chrome $(\mathrm{Cr})$, cadmium $(\mathrm{Cd})$, mercury $(\mathrm{Hg})$ and lead $(\mathrm{Pb})$, with the color of wastewater containing the highest $\mathrm{Cu}$ selected.

\subsection{Adsorbent preparation}

The leaves and shoot parts of the selected water hyacinth weeds were separated and washed with aqua dest and running water to remove impurities. After cleaning, the next process was to cut the leaves into small pieces. It then dried with the sun (around 2-3 days) to reduce the moisture. This was followed by tanur-drying at a temperature of $400^{\circ} \mathrm{C}$ for 2 hours to form charcoal. After that, the leaves were mashed in a uniform size and sieved with 100 meshes. The pulverized charcoal was inserted into the desiccator.

\subsection{Activation of Adsorbent}

Carbonized water hyacinth leaves were activated by using $\mathrm{H}_{2} \mathrm{SO}_{4}$ solution with a $20 \%$ concentration. The amount of activated adsorbate and adsorbent were $2 \mathrm{ml}$ : 1 gram. The adsorbent was activated by soaking the leaves in $20 \% \mathrm{H}_{2} \mathrm{SO}_{4}$ solution for 24 hours. The leaves were then washed by using distilled water. The oven dried at $110^{\circ} \mathrm{C}$ for 2 hours

\subsection{Mixing Speed Optimization and Contact Time}

$\mathrm{Cu}$-wastewater of $250 \mathrm{ml}$ in ranges of 100,150 , and 200 were used to optimize the mixing speed. Furthermore, the powdered form of the leaves was added using a jartest at a contact time of 30 and 60 as well as 90 minutes. ASS was used to examine theremaining $\mathrm{Cu}$ metal in the solution.

\subsection{Mass Adsorbent Optimization and Contact Time}

Mass weight optimization was conducted in a batch system using The $\mathrm{Cu}$-wastewater weighing $250 \mathrm{ml}$ at a mixing speed of $100 \mathrm{rpm}$, was used to examine the optimize the mass weight. In addition, the mass weight of the adsorbent which was set in ranges of 10,15 , and 20 grams was added using a jartest with a of 30,60 , and 90 minutes contact time. The remaining $\mathrm{Cu}$ metal in the solution was analyzed using AAS.

\subsection{Adsorption of $\mathrm{Cu}$}

\subsubsection{Cu Removal Efficiency}

Equation (1) and (2) show the calculation of the removal efficiency and adsorption capacity [7]:

$q_{e}=\frac{\left(C_{o}-C_{e}\right) V}{W}$

Removal efficiency $(\%)=\frac{\left(C_{o}-C_{e}\right)}{C_{o}} 100 \%$

$\mathrm{q}_{\mathrm{e}}=$ The equilibrium adsorption capacity $\left(\mathrm{mg} \mathrm{g}^{-1}\right)$

$\mathrm{C}_{\mathrm{o}}=$ Initial concentrations

$\mathrm{C}_{\mathrm{e}}=$ Equilibrium concentrations $(\mathrm{mg} / \mathrm{L})$

$\mathrm{V}=$ Volume of the solution $(\mathrm{L})$

$\mathrm{W}=$ The weight of the adsorbent $(\mathrm{g})$.

\subsubsection{Adsorption Isotherms}

Adsorption isotherm contains information on the adsorption mechanism, between the solid and liquid phases. The interaction between two adsorption phases of $\mathrm{Cu}$ were also determined using the Langmuir and Freundlich adsorption isothermal models as illustrated by equations (3) and (4) respectively [8]:

$C_{e} / q_{e}=C_{e} / q_{m}+1 /\left(q_{m} \cdot K_{l}\right)$

$\ln q_{e}=\ln K_{f}+(1 / n) \cdot\left(\ln C_{e}\right)$

$\mathrm{q}_{\mathrm{e}}=$ The amount of $\mathrm{Cu}$ ions adsorbed $\left(\mathrm{mg} \mathrm{g}^{-1}\right)$

$\mathrm{Ce}=$ The concentration and equilibrium of $\mathrm{Cu}$ ion $(\mathrm{mg} / \mathrm{L})$ $\mathrm{q}_{\mathrm{m}}=$ the maximum adsorption capacity of the adsorbent $\left(\mathrm{mg} \mathrm{g}^{-1}\right)$

$\mathrm{K}_{\mathrm{L}}=$ The isotherm constants of Langmuir

$\mathrm{K}_{\mathrm{F}}=$ The isotherm constants Freundlich $(\mathrm{L} / \mathrm{mg})$

$\mathrm{N}=$ The heterogeneity factor that shows the capacity and intensity of the adsorption.

\subsubsection{Adsorption Kinetics}

The adsorption rates were investigated to characterize the adsorbent speed. The pseudo-first and second-order models were selected to discover the kinetic adsorption behavior, which assumes that the ion is adsorbed at single and double surface locations, respectively. The comparisons for kinetic models are stated below [7]:

Pseudo-first-order:

$\log \left(q_{e}-q_{t}\right)=\log q_{e} \frac{k_{1}}{2.303} t$

Pseudo-second-order:

$\frac{t}{q_{t}}=\frac{1}{k_{2} q_{e}^{2}}+\frac{1}{q_{e}} t$

$\mathrm{q}_{\mathrm{e}}, \mathrm{q}_{\mathrm{t}}=$ Ssolute adsorbed at equilibrium $\left(\mathrm{mg} \mathrm{g}^{-1}\right)$ 
$\mathrm{k}_{1}=$ Adsorption constant $\left(\mathrm{min}^{-1}\right)$,

$\mathrm{k}_{2}=$ The pseudo-second-order adsorption rate constant ( $\mathrm{g}$ $\left.\mathrm{mg}^{-1} \min ^{-1}\right)$.

$\mathrm{t}=$ Time (minutes)

\section{Result and Discussion}

\subsection{Wastewater Characterization}

Samples were obtained from different phases of the screen printing washing process. The wastewater of each color contains different heavy metal contents. In the wash phase, blue was particularly high in $\mathrm{Cu}(1.67 \mathrm{mg} / \mathrm{l})$. The different color samples of the copper content in each sewer are shown in Table 1.

Table 1: Copper with different colors

\begin{tabular}{|c|c|c|c|}
\hline Colors & Parameters & Unit & Result \\
\hline Yellow & \multirow{5}{*}{$\mathrm{Cu}$} & \multirow{5}{*}{$\mathrm{mg} / \mathrm{l}$} & 0.0384 \\
\hline Blue & & & 1.6755 \\
\hline White & & & 0.0017 \\
\hline Red & & & 0.205 \\
\hline Black & & & 0.0069 \\
\hline
\end{tabular}

From the analysis, it was obtained that the blue wastewater contained the highest heavy metals with a $\mathrm{Cu}$ concentration of $1,6755 \mathrm{mg} / \mathrm{l}$. This amount is below the standard quality of water according to Law number 5 on the regulations of the Minister of Environment, Republic of Indonesia number in the paint industry. The permitted concentration of $\mathrm{Cu}$ is less than $0.8 \mathrm{mg} / \mathrm{l}$.

\subsection{Removal Efficiency of $\mathrm{Cu}$}

\subsubsection{Effect of mixing speed and contact time}

The mixing speed is determined to obtain the optimum stirring speed in adsorbing copper metal by water hyacinth leaves. This study used a mixing speed of 100,150 , and $200 \mathrm{rpm}$, respectively with a contact time of 30,60 , and 90 minutes. The effect of mixing speed and contact time on copper adsorption efficiency is shown in Figure 1.

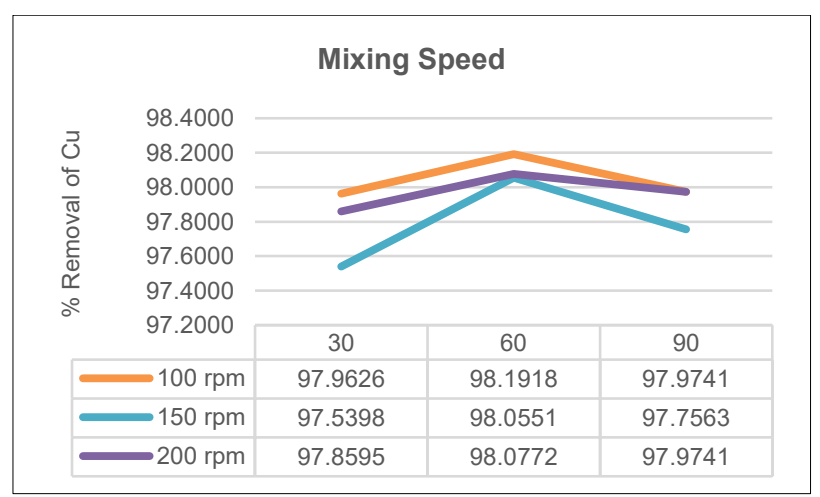

Fig. 1: Effect of Mixing Speed and Contact Time on $\mathrm{Cu}$ removal efficiency.
Fig. 1 shows the maximum $\mathrm{Cu}$ removal efficiency of $98.19 \%$ was observed at a mixing speed of $100 \mathrm{rpm}$ and a contact time of 60 minutes. The adsorbents and adsorbates were evenly spread to reduce the levels of heavy metal and make $\mathrm{Cu}$ more effective. Initially, all active sites in the adsorbent were empty, therefore the adsorption was faster, while the desorption was lower, thereby, leading to a faster increase in the degree of adsorption. Due to the occupied nature of the active sites, the degree of adsorption is lowered and ultimately becomes virtually constant in equilibrium. [21].

\subsubsection{Effect of mass adsorbent and contact time}

The adsorbent mass of a fixed amount of adsorbate, has the ability to absorb the solution initial concentration. $\mathrm{Cu}$ adsorption by water hyacinth leaf powder was studied in ranges of 10, 15 and 20 grams. The effect of initial concentrations of $\mathrm{Cu}$ ions is shown ini Figure 2 .

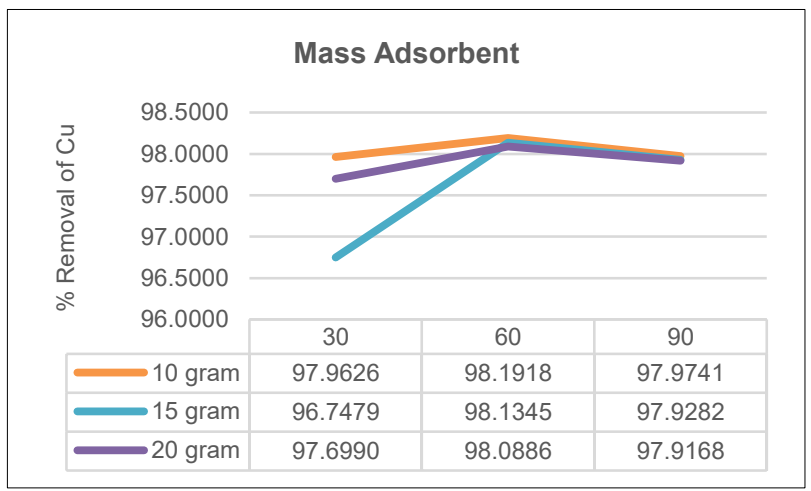

Fig. 2 Effect of Mass Adsorbent and Contact Time on $\mathrm{Cu}$ removal efficiency

The experiments were performed at an optimum mixing speed of $100 \mathrm{rpm}$ by adding 10, 15 and 20 grams of adsorbents in the flasks containing $250 \mathrm{ml}$ of $\mathrm{Cu}$ solution. The effect of the adsorbent mass on the removal of $\mathrm{Cu}$ ions as well as its extraction rise by $98.19 \% \mathrm{Cu}$ is shown in Figure 2. However, there was a decrease in the amount of adsorbed $\mathrm{Cu}$ per unit with an increase as the adsorbent. Therefore, for the additional adsorption processes, an adsorbent mass of 10 grams was chosen as the optimum weight. At higher adsorbent doses of 15 and 20 grams, there are limited $\mathrm{Cu}$ in the solution, therefore, the adsorption is constant [21].

The water hyacinth leaf also known as $E$. crassipes, is a powerful grower, that doubles its population within two weeks. It is cost-efficient and available for the treatment of dyes and effluents. This herb and its various forms, changes have been investigated to increase effectiveness. However, a detailed study of different wastewater and modified forms has the ability to produce simple, better and cheaper water hyacinth with metal effluents in the near future [17].

\subsection{Adsorption Isotherms}

To analyze the adsorption capacity, the Langmuir and Freundlich methods were graphically represented. 
According to the Langmuir isotherm, the monolayer adsorption of a homogeneous surface is used to determine the finite number of sites without interaction between the adsorbed molecules [18]. Adsorption isotherms describe the balance between adsorbent and adsorbate. Figures 3 and 4, shows the mixing speed and mass of Langmuir adsorption isotherm, respectively.

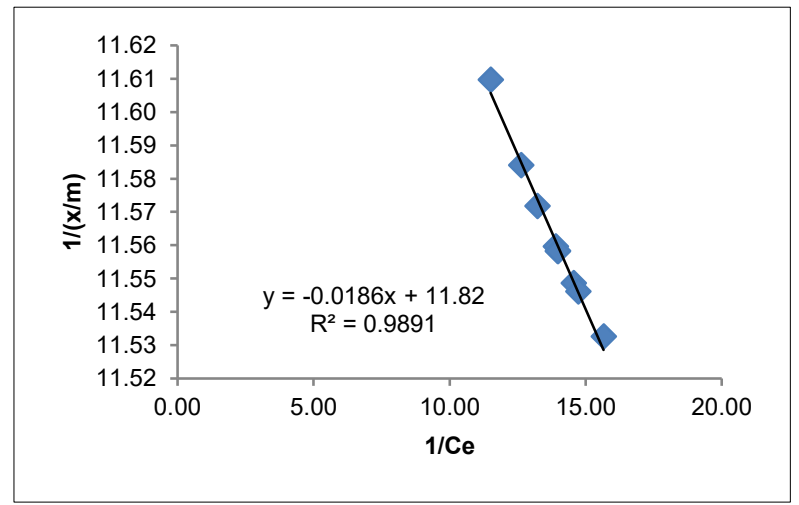

Fig 3: Langmuir adsorption isotherm of water hyacinth leaves adsorbent with mixing speed variations

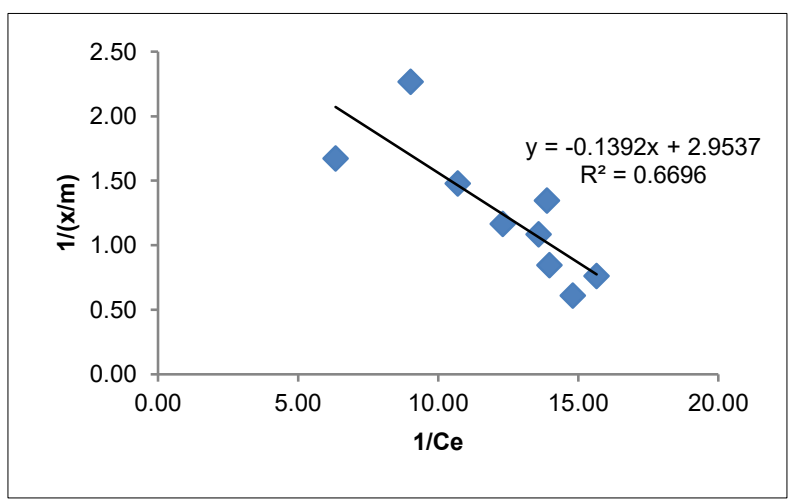

Fig 4: Langmuir adsorption isotherm of water hyacinth leaves adsorbent with a mass of adsorbent variations

The adsorption process was analyzed by using the Freundlich isotherm model which consists of a multilayer distribution process of the adsorbed molecules [18]. Freundlich adsorption isotherm with mixing speed and mass of adsorbent variations is seen in Figures 5 and 6, respectively.

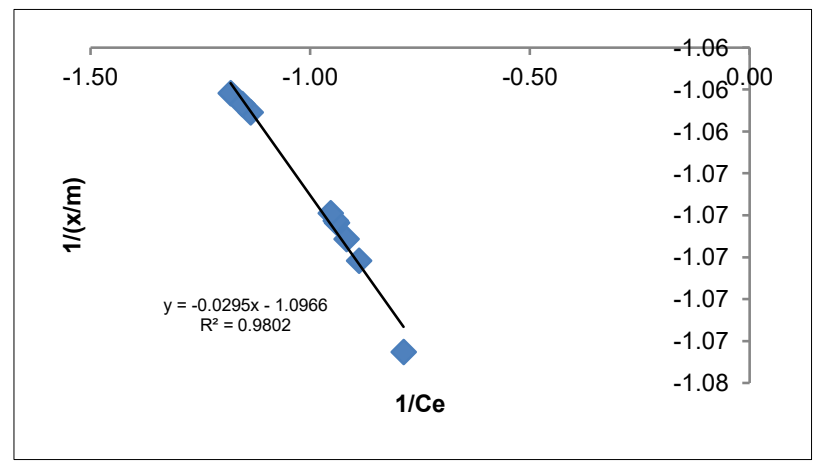

Corresponding author: rianaayu.kusumadewi @trisakti.ac.id
Fig 5: Freundlich adsorption isotherm of water hyacinth leaves adsorbent with mixing speed variations

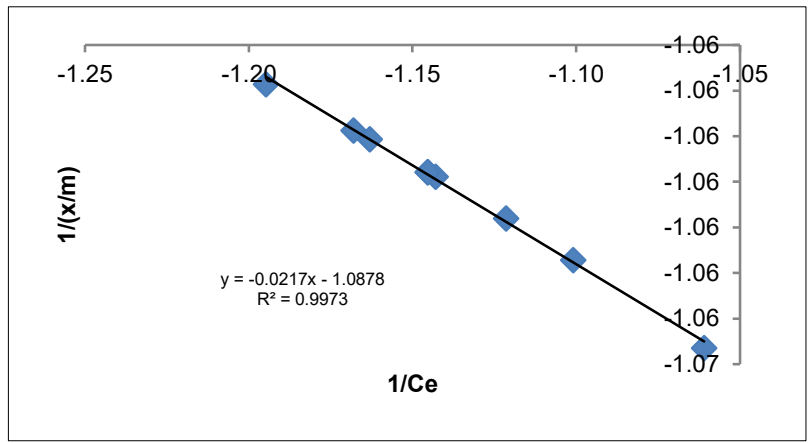

Fig 6: Freundlich adsorption isotherm of water hyacinth leaves adsorbent with a mass of adsorbent variations

The adsorption process used to $\operatorname{mix} \mathrm{Cu}$ is in close agreement with Freundlich isotherm model (Fig. 3, 4, 5, $6)$. The coefficient correlation $\left(\mathrm{R}^{2}\right)$ values of Freundlich was 0.98 (mixing speed variations) and 0.997 (mass of adsorbent variations), while Langmuir isotherm was 0.989 (mixing speed variations) and 0.669 (mass of adsorbent variations), respectively. The coefficient correlation $\left(\mathrm{R}^{2}\right)$ for the Freundlich isotherm curve was closer to 1 , and the linear line. The $\mathrm{R}^{2}$ values for Freundlich adsorption isotherm model were closer to unity (0.98 and 0.997$)$, therefore, the adsorption of $\mathrm{Cu}$ onto the adsorbent was heterogeneous and multilayer in nature. The Isotherm Freundlich constant exhibits adsorption capacity at heterogeneous locations with an uneven distribution of the energy level [9]. It assumes that metal ion adsorption occur on a heterogeneous surface with multi-layer adsorption which increases with a rise in concentration [19]. In addition, there is physical adsorption, which means that it occurs on the surface of the absorbent.

The value of $\mathrm{n}$ is a constant feature of the adsorption system being studied [20]. When the value of $n$ is above 1 , it shows a favorable adsorption, and when it is below 1 it represents poor characteristics. The value of $n$ in this study is -33.9 , therefore, the adsorption characteristics with water hyacinth leaves are relatively poor.

The outcome values parameters $\mathrm{q}_{\mathrm{m}}, \mathrm{b}, \mathrm{R}^{2}$, and $\mathrm{K}_{\mathrm{f}}$ for all experiments using the Freundlich equation, are shown in Table 2.

Table 2: Adsorption equilibrium parameters

\begin{tabular}{|c|c|c|c|c|c|c|}
\hline \multirow{2}{*}{$\begin{array}{l}\text { The parameters of } \\
\text { adsorption }\end{array}$} & \multicolumn{3}{|c|}{$\begin{array}{c}\begin{array}{c}\text { Langmuir adsorption } \\
\text { isotherm }\end{array} \\
\end{array}$} & \multicolumn{3}{|c|}{ Freundlich adsorption isotherm } \\
\hline & $\begin{array}{c}q_{m}(m g \\
\left.g^{-1}\right)\end{array}$ & b & $\mathbf{R}^{2}$ & $\begin{array}{c}\mathrm{K}_{\mathrm{f}}\left(\mathrm{mg} \mathrm{g}^{-1}\right. \\
(\mathrm{l} / \mathrm{g})^{1 / 1 / 1}\end{array}$ & $1 / \mathrm{n}$ & $\mathbf{R}^{2}$ \\
\hline $\begin{array}{c}\text { Mixing speed } \\
\text { Mass adsorbent }\end{array}$ & $\begin{array}{l}635.48 \\
22.19\end{array}$ & $\begin{array}{l}0.08 \\
0.33\end{array}$ & $\begin{array}{l}0.989 \\
0.669\end{array}$ & $\begin{array}{l}3.47 \\
3.46 \\
\end{array}$ & $\begin{array}{l}-0.0295 \\
-0.0217\end{array}$ & $\begin{array}{l}0.980 \\
0.997\end{array}$ \\
\hline
\end{tabular}

\subsection{Adsorption Kinetics}

The remaining concentration rates in the wastewater were used to measure the adsorption rate of $\mathrm{Cu}$ ions at different time intervals till the equilibrium value was attained. The data were adjusted with different kinetic comparisons, namely, Pseudo first and second orders as shown in Figures 7 and 8. 


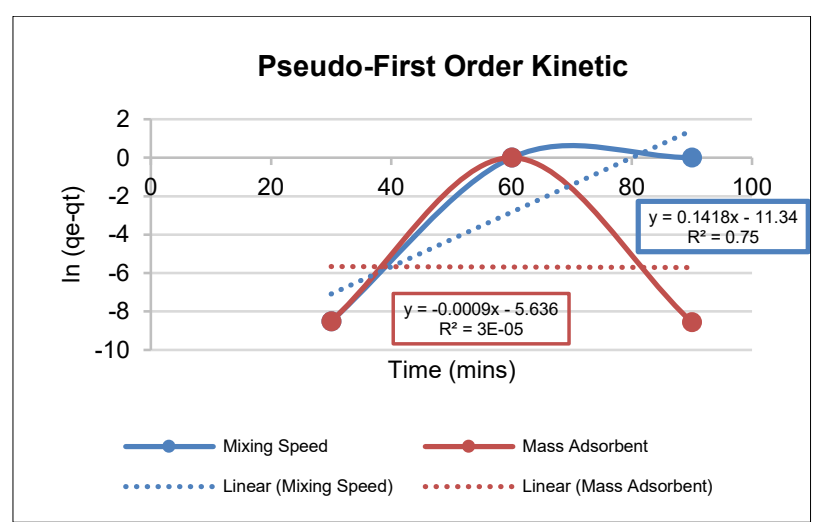

Fig 7: Removal of $\mathrm{Cu}$ kinetics according to the pseudofirst-order model

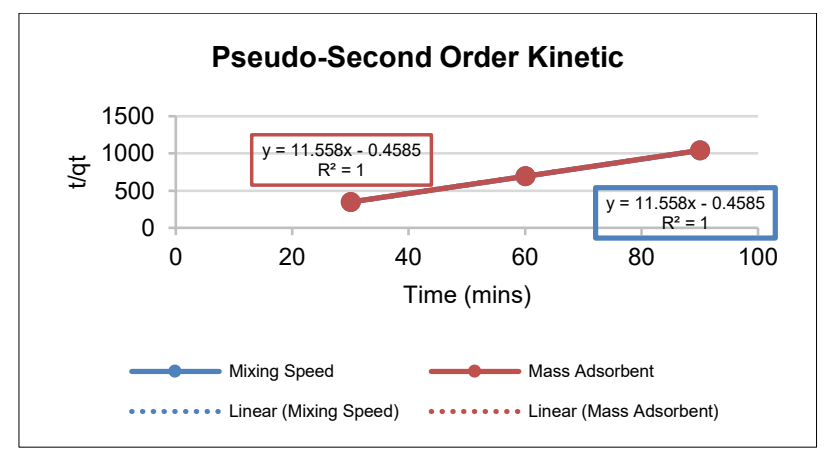

Fig 8: Removal of $\mathrm{Cu}$ kinetics according to the pseudosecond-order model

The graphical representations of the kinetic models for the adsorption of $\mathrm{Cu}$ compounds shows is Figures 7, 8, table 3. The correlation coefficient of the second-order model was high using $\mathrm{R}^{2}$ with a value of 1 . Conversely, the qe value of the second-order model was used in the experimental data and suitable for $\mathrm{Cu}$ adsorption in the adsorbent.

Table 3: Adsorption kinetic parameters

\begin{tabular}{|c|c|c|c|c|c|c|c|}
\hline \multirow{2}{*}{$\begin{array}{c}\text { The } \\
\text { parameters } \\
\text { of } \\
\text { adsorption }\end{array}$} & \multirow[b]{2}{*}{$\begin{array}{l}\text { qe, exp } \\
\left(\mathrm{mg} \mathrm{g}^{-1}\right)\end{array}$} & \multicolumn{3}{|c|}{$\begin{array}{l}\text { Pseudo-first-order kinetic } \\
\text { model }\end{array}$} & \multicolumn{3}{|c|}{$\begin{array}{c}\text { Pseudo-second-order } \\
\text { kinetic model }\end{array}$} \\
\hline & & $\begin{array}{c}\mathbf{k}_{1}(\mathbf{x} \\
\left.10^{3}\right) \\
\left(\mathrm{min}^{-1}\right)\end{array}$ & $\begin{array}{l}\text { qe, cal } \\
\left(\mathrm{mg} \mathrm{g}^{-1}\right)\end{array}$ & $\mathbf{R}^{2}$ & $\begin{array}{c}\mathbf{k}_{2}\left(\mathbf{x} 10^{-6}\right) \\
\left(\mathrm{g} \mathrm{mg}^{-}\right. \\
\left.\mathrm{imin}^{-1}\right)\end{array}$ & $\begin{array}{l}\text { qe, } \\
\text { cal } \\
\left(\mathrm{mg}^{-1}\right. \\
\left.\mathrm{g}^{-1}\right)\end{array}$ & $\mathbf{R}^{2}$ \\
\hline \multirow{2}{*}{$\begin{array}{c}\text { Mixing speed } \\
\text { Mass } \\
\text { adsorbent } \\
\end{array}$} & 0.087 & -0.014 & $1.19 \mathrm{E}-05$ & 0.75 & -291.36 & 0.09 & 1 \\
\hline & 0.087 & 0.001 & 3.57E-03 & 1 & -291.36 & 0.09 & 1 \\
\hline
\end{tabular}

\subsection{Quality of treated wastewater}

Water quality refers to its chemical, physical, biological and radiological properties. In this study, the $\mathrm{Cu}$ content of heavy metals after the adsorption process was tested. Water quality after the adsorption process is shown in Table 4.

Table 4: Quality of treated wastewater

\begin{tabular}{|c|c|c|c|c|c|}
\hline \multicolumn{6}{|c|}{ Hyacinth Leaves Adsorbent } \\
\hline $\begin{array}{c}\text { Mixing } \\
\text { Speed } \\
\text { Optimum } \\
\text { (rpm) }\end{array}$ & $\begin{array}{c}\text { Contact } \\
\text { Time } \\
\text { (mins) }\end{array}$ & $\begin{array}{c}\text { Untreated } \\
\text { wastewater } \\
\text { Conc. }(\mathrm{mg} / \mathrm{l})\end{array}$ & $\begin{array}{c}\begin{array}{c}\text { Mass of } \\
\text { Adsorbent } \\
\text { (grams) }\end{array} \\
\text {. }\end{array}$ & $\begin{array}{c}\text { Treated } \\
\text { wastewater } \\
\text { Conc. }(\mathrm{mg} / \mathrm{l})\end{array}$ & $\begin{array}{l}\text { Removal } \\
\text { Eff. (\%) }\end{array}$ \\
\hline \multirow{7}{*}{100} & 30 & \multirow{7}{*}{1.6755} & \multirow{3}{*}{10} & 0.0716 & 97.97 \\
\hline & 60 & & & 0.0639 & 98.19 \\
\hline & 90 & & & 0.0716 & 97.97 \\
\hline & 30 & & \multirow{3}{*}{15} & 0.0813 & 97.69 \\
\hline & 60 & & & 0.0675 & 98.08 \\
\hline & 90 & & & 0.0736 & 97.91 \\
\hline & 30 & & 20 & 0.0158 & 95.53 \\
\hline
\end{tabular}

*Corresponding author: rianaayu.kusumadewi @trisakti.ac.id

\begin{tabular}{|c|c|c|c|c|c|}
\hline \multicolumn{7}{|c|}{ Hyacinth Leaves Adsorbent } \\
\hline $\begin{array}{c}\text { Mixing } \\
\text { Speed } \\
\text { Optimum } \\
\text { (rpm) }\end{array}$ & $\begin{array}{c}\text { Contact } \\
\text { Time } \\
\text { (mins) }\end{array}$ & $\begin{array}{c}\text { Untreated } \\
\text { wastewater } \\
\text { Conc. (mg/l) }\end{array}$ & $\begin{array}{c}\text { Mass of } \\
\text { Adsorbent } \\
\text { (grams) }\end{array}$ & $\begin{array}{c}\text { Treated } \\
\text { wastewater } \\
\text { Conc. (mg/l) }\end{array}$ & $\begin{array}{c}\text { Removal } \\
\text { Eff. (\%) }\end{array}$ \\
\hline & 60 & & & 0.0934 & 97.35 \\
\cline { 5 - 7 } & 90 & & & 0.1108 & 96.86 \\
\hline
\end{tabular}

The quality of untreated wastewater that indicated blue was especially high in $\mathrm{Cu}(1.67 \mathrm{mg} / \mathrm{l})$ and after treated with wastewater at an optimum mixing speed of $100 \mathrm{rpm}, 10$ grams mass adsorbent and contact time of 60 minutes it produced a heavy metal with and efficiency of $98.19 \%$ and final concentration of $0.0639 \mathrm{mg} / \mathrm{l}$. The quality of the water produced after the adsorption process using the leaves was in accordance with the regulations of the Minister of the Environment on standards for sewage in the paint industry. Therefore, the heavy metal concentration limit $\mathrm{Cu}$ is $0.8 \mathrm{mg} / \mathrm{l}$.

\section{Conclusion}

In conclusion, the mass of water hyacinth leaves contains an adsorbing character that functions as a heavy metal binder, such as $\mathrm{Cu}$. Its adsorbents are promising due to the ability of the $\mathrm{Cu}$ to reserve at an optimum mixing speed of $100 \mathrm{rpm}$ with a contact time of 60 minutes. It was therefore found that the bulk adsorbent of the optimum 10-gram water hyacinth leaves increases the sorption process compared to the free adsorbent. The effective parameters of the adsorption processes such as contact time (30, 60, 90 minutes), mixing speed (100, 150, 200 $\mathrm{rpm})$, and mass adsorbent (10, 15, 20 grams) were studied in the batch experiment. Therefore, the optimum removal of $\mathrm{Cu}$ ions from the wastewater using 10 grams of adsorbent mass, 60 minutes of contact time, $100 \mathrm{rpm}$ of mixing speed, was obtained for $250 \mathrm{ml}$ with initial concentration solutions of $98.19 \%$. The balance data was properly represented in the Freundlich adsorption isotherm, while the pseudo-second-order model was adapted when the kinetic models for $\mathrm{Cu}$ adsorption were analyzed. The quality of water produced after the adsorption process using the leaves met the standard quality regulated by the Minister of Environment.

\section{References}

[1] D.E. Kimbrough, Y. Cohen, A.M. Winer, L. Crelman, C. Mabuni, A critical assessment of chromium in the environment, Crit. Rev. Environ. Sci. Technol. 29 (1999) 1-46.

[2] Oboh I, Aluyor E, Udu T, "Biosorption of Heavy Metal Ions from Aqueous Solutions Using a Biomaterial”, Leonardo J. Sci, Vol. 14, 2009, pp. 5865, ISSN 1583-0233.

[3] Velásquez L, Dussan J, "Biosorption and Bioaccumulation of Heavy Metals on Dead and Living Biomass of Bacillus sphaericus", J. Hazard. Mater, Vol. 167, 2009, pp. 713-716.

[4] Eccles H, "Treatment of Metal-Contaminated Wastes: Why Select a Biological Process?", Trends Biotechnol, Vol. 17, 1999, pp. 462-465.

[5] Gadd GM, "Biosorption : Critical Review of Scientific Rationale, Environmental Importance and 
Significance for Pollution Treatment", J. Chem. Technol. Biotechnol, Vol. 84, 2009, pp. 13-28.

[6] Rinanti, Astri, Melati Ferianita Fachrul, Rositayanti Hadisoebroto, dan Mawar Silalahi. 2017. Improving Biosorption of $\mathrm{Cu}(\mathrm{II})$-Ion Artificial Wastewater By Immobilized Biosorbent Of Tropical Microalgae. Japan: International Journal of Geomate, Vol.13 Issue 36.

[7] N. Arancibia-Miranda, J. Silva-Yumi, M. Escudey, Effect of cations in the background electrolyte on the adsorption kinetics of copper and cadmium and the isoelectric point of imogolite, J. Hazard. Mater. 299 (2015) 675-684.

[8] Z.A. Sutirman,M.M. Sanagi, K.J.A. Karim,W.A.W. Ibrahim, B.H. Jume, Equilibrium, kinetic andmechanismstudies of $\mathrm{Cu}$ (II) and $\mathrm{Cd}(\mathrm{II})$ ions adsorption bymodified chitosan beads, Int. J. Biol. Macromol. 116 (2018) 255-263.

[9] Prastika, Alifaturrahma dan Okik, Hendriyanto C .2016. Utilization of Kepok Banana Skin as an Adsorbent to Removing $\mathrm{Cu}$. Environmental Engineering Journal, 8 (2): 105-111.

[10] Fitriani, D., D. Oktiarni., dan Lusiana. 2015.Utilization Of Banana Skins As Methylene Blue Dyes Adsorbent. Journal Gradien. 11(2): 10911095.

[11] H. Ucun, O. Aksakal, E. Yildiz, Copper(II) and zinc(II) biosorption on Pinus sylvestris L., J. Hazard. Mater. 161 (2009) 1040-1045.

[12] Hossain,M. A., H. H. Ngo, W. S. Guo and T. V. Nguyen.2012.Removal of Copper from Water by Adsorption onto Banana Peel as Bioadsorbent.Int.J.Of Geomate, EOMATE, 2(2) : 227-234.

[13] Maleki, Afshin., B Hayati., M Naghizadeh., S.W Joo. 2015. Adsorption of hexavalent chromium by metal organic frameworks from aqueous solution. Journal of Industrial and Engineering Chemistry. 28:211-216.

[14] N.C. Feng, X.Y. Guo, S. Liang, Adsorption study of copper(II) by chemically modified orange peel, J. Hazard. Mater. 164 (2009) 1286-1292.

[15] Parmar,M.and L.S. Thakur.2013.Heavy Metal Cu, Ni And Zn: Toxicity, Health Hazards And Their Removal Techniques By Low Cost Adsorbents: A Short Overview.International Journal of Plant, Animal and Environmental Sciences.
[16] Siwi, Widyanigrum Permata. 2016. Effect of Biosorbent Immobilization on Absorption of Copper Heavy Metal $(\mathrm{Cu} 2+)$ with Temperature Variations and Initial Concentration of Waste. Jakarta: Teknik Lingkungan, Fakultas Arsitektur Lanskap dan Teknologi Lingkungan.Universitas Trisakti.

[17] E.S. Priya and P.S. Selvan, Water Hyacinth (Eichhornia crassipes) - An Efficient and Economic Adsorbent for Textile Effluent Treatment - A Review , Arabian Journal of Chemistry (2017) 10, S3548-S3558.

[18] H. Panda, N. Tiadi, M. Mohanty, C.R. Mohanty, Studies on Adsorption Behavior of An Industrial Waste for Removal of Chromium from Aqueous Solution, South African Journal of Chemical Engineering (2017) 23, 132-138.

[19] A. Ali, K. Saeed, and F. Mabood, Removal of Chromium (VI) from Aqueous Medium using Chemically Modified Banana Peels as Efficient Low-Cost Adsorbent, Alexandria Engineering Journal (2016) 55, 2933-2942.

[20] O.E.A. Salam, N.A. Reiad, and M.M. ElShafei, A Study of The Removal Characteristics of Heavy from Wastewater by Low-Cost Adsorbents, Journal of Advanced Research (2011) 2, 297-303.

[21] M.K. Rai, G. Shahi, V. Meena, R. Meena, S. Chakraborty, R.S. Singh, and B.N. Rai, Removal of Hexavalent Chromium $\mathrm{Cr}(\mathrm{VI})$ using Activated Carbon Prepared from Mango Kernel Activated with $\mathrm{H}_{3} \mathrm{PO}_{4}$, Resource-Efficient Technologies (2016) 2, S63-S70.

[22] Mukimin, A., Zen, N., Purwanto, A., Wicaksono, K. A., Vistanty, H., \& Alfauzi, A. S. (2017). Application of a full-scale electrocatalytic reactor as real batik printing wastewater treatment by indirect oxidation process. Journal of Environmental Chemical Engineering, 5(5), 52225232.

[23] Birgani, P. M., Ranjbar, N., Abdullah, R. C., Wong, K. T., Lee, G., Ibrahim, S., Jang, M. (2016). An efficient and economical treatment for batik textile wastewater containing high levels of silicate and organic pollutants using a sequential process of acidification, magnesium oxide, and palm shellbased activated carbon application. Journal of Environmental Management, 184, 229-239. 